\title{
RBOHF2 of Barley Is Required for Normal Development of Penetration Resistance to the Parasitic Fungus Blumeria graminis f. sp. hordei
}

\author{
Reinhard K. Proels, ${ }^{1}$ Kathrin Oberhollenzer, ${ }^{1}$ Indira Priyadarshini Pathuri, ${ }^{1}$ Götz Hensel, ${ }^{2}$ \\ Jochen Kumlehn, ${ }^{2}$ and Ralph Hückelhoven ${ }^{1}$ \\ ${ }^{1}$ Lehrstuhl für Phytopathologie, Technische Universität München, Emil-Ramann-Straße 2, D-85350 Freising-Weihenstephan, \\ Germany; ${ }^{2}$ Leibniz Institute of Plant Genetics and Crop Plant Research (IPK), Corrensstraße 3, D-06466 Gatersleben, \\ Germany
}

Submitted 4 February 2010. Accepted 5 May 2010.

\begin{abstract}
Plant respiratory burst oxidase homologs are prominent sources of reactive oxygen species (ROS) in signal transduction and in interaction with microbes. However, the function of respiratory burst oxidase homologue $(\mathrm{RBOH})$ genes in interaction with microbes might differ for certain plant and pathogen species. We produced transgenic barley knock down (KD) for the HvRBOHF2 isoform of NADPH oxidases. Young HvRBOHF2 KD shoots did not show obvious morphological alterations from the wild type but adult $H v R B O H F 2$ KD plants developed fewer tillers, were less fertile, and showed spontaneous cell death in leaf mesophyll. Additionally, $\mathrm{HvRBOHF2} \mathrm{KD}$ plants were unable to contain wound-induced cell death. Before developmental failure became obvious, young $\mathrm{HvRBOHF2} \mathrm{KD}$ seedlings were much more susceptible to penetration by the biotrophic powdery mildew fungus Blumeria graminis f. sp. hordei. Strikingly, the B. graminis f. sp. hordeiinduced cell-wall-associated oxidative burst was not substantially attenuated in $\mathrm{HvRBOHF2} \mathrm{KD}$ plants but enhanced susceptibility apparently influenced the subcellular site of hydrogen peroxide accumulation. Taken together, misexpression of $\mathrm{HvRBOHF2}$ caused failure of barley to normally develop penetration resistance to $B$. graminis $f$. sp. hordei and to control leaf cell death.
\end{abstract}

In plants, the apoplastic oxidative burst is one of the earliest events in response to pathogenesis- or damage-associated molecular patterns. A rapid, transient production of reactive oxygen species (ROS) in cell cultures or detached leaves after elicitor perception or mechanical stress is detected in biochemical assays or can be histochemically detected at sites of plant-microbe interactions. ROS are involved in defense gene expression, phytoalexin production, and both hypersensitive reaction (HR) and the restriction of pathogen-induced cell death (Lamb and Dixon 1997; Torres et al. 2006).

Major sources for plant defense-related ROS production are phagocyte respiratory burst oxidase homologous (RBOH) NADPH oxidases (also called NOX in fungi and animals), peroxidases, amine oxidases, and oxalate oxidases. ROS are key

Corresponding author: Ralph Hückelhoven;

E-mail: hueckelhoven@wzw.tum.de

* The $\boldsymbol{e}$-Xtra logo stands for "electronic extra" and indicates that Figures 3 and 5 appear in color online. molecules in signaling and the biochemistry of nonspecific plant defense. $\mathrm{H}_{2} \mathrm{O}_{2}$ is required for peroxidase-dependent lignification and for protein cross-linking in the cell wall. Attack by fungal pathogens also induces the expression of peroxidases, which can reside in cell wall appositions where they might contribute to formation of physical or biochemical barriers for pathogen invasion (An et al. 2006; Torres et al. 2006).

Superoxide-producing RBOH oxidases appear as key proteins in defense-related ROS production. Arabidopsis AtRBOHD and AtRBOHF contribute to HR in interactions with avirulent $\mathrm{Pseu}$ domonas syringae. In contrast, AtRBOHD and AtRBOHF have additional roles in restricting pathogenesis-related cell death in interaction with necrotrophic fungi (Torres et al. 2005; Pogány et al. 2009), and atrbohF mutants display enhanced HR and enhanced adult resistance to Hyaloperonospora parasitica Emco5 but unaltered accumulation of $\mathrm{H}_{2} \mathrm{O}_{2}$ (Torres et al. 2002). In contrast, AtRBOHD also constitutes a major ROS-producing enzyme in response to the flagellin elicitor and pathogen (Torres et al. 2002; Nühse et al. 2007; Achard et al. 2008; Pogány et al. 2009). Silencing of $R B O H A$ and $R B O H B$ in Nicotiana benthamiana leads to weakening of nonhost resistance to Phytophthora infestans (Yoshioka et al. 2003).

For monocots, little genetic evidence exists for the function of RBOH oxidases. Silencing of OSRBOHA or OsRBOHE in cultured rice cells significantly dampened the oxidative burst, $\mathrm{HR}$, and pathogenesis-related gene expression (Yoshie et al. 2005). Transient co-expression of OsRBOHB and a constitutively activated regulatory small G-protein OsRAC1 in N. benthamiana cooperatively enhanced ROS production (Wong et al. 2007). Transient silencing of HvRBOHF2 (synonym: $H v R B O H A$ ) reduced penetration success of Blumeria graminis f. sp. hordei in epidermal cells of barley (Trujillo et al. 2006). Stable transgenic expression of constitutively activated HvRAC1 in barley rendered plants more susceptible to $B$. graminis f. sp. hordei than the wild type and supported secondary $\mathrm{H}_{2} \mathrm{O}_{2}$ accumulation in cells dying after fungal attack (Pathuri et al. 2008). Recently, six members of the barley $R B O H$ family have been identified, and expression of two of them ( $H v R B O H F 1$ and $H v R B O H F 2)$ appeared slightly induced after inoculation with necrotrophic leaf pathogens and $B$. graminis f. sp. hordei (Trujillo et al. 2006; Lightfoot et al. 2008). Together, plant $\mathrm{RBOH}$ oxidases are involved in pathogen-triggered ROS production and have regulatory functions in cell death and defense responses. Other roles of plant $\mathrm{RBOH}$ oxidases are in systemic signaling and wound responses; development of shoots, flowers, and fruit; and stomata closure (Murata et al. 2001; Torres 
et al. 2002; Sagi et al. 2004; Desikan et al. 2006; Miller et al. 2009). In root hairs and pollen tubes, $\mathrm{RBOH}$ oxidases are crucial for establishment and maintenance of polarity (Foreman et al. 2003; Potocký et al. 2007).

ROS production was intensively studied in compatible and incompatible interactions of barley with $B$. graminis, the obligate biotrophic grass powdery mildew fungus. Histochemical analyses revealed different spatiotemporal patterns of $\mathrm{H}_{2} \mathrm{O}_{2}$ and $\mathrm{O}_{2}{ }^{-}$production, respectively (Hückelhoven and Kogel 1998; Hückelhoven et al. 1999; Trujillo et al. 2004). $\mathrm{H}_{2} \mathrm{O}_{2}$, as evidenced by localized oxidation of the dye 3,3-diamonobenzidine, was associated with formation of cell wall appositions (CWA, synonymous: papillae) and HR cell death (Thordal-Christensen et al. 1997). The presence of $\mathrm{H}_{2} \mathrm{O}_{2}$ in CWA appeared as a bio-
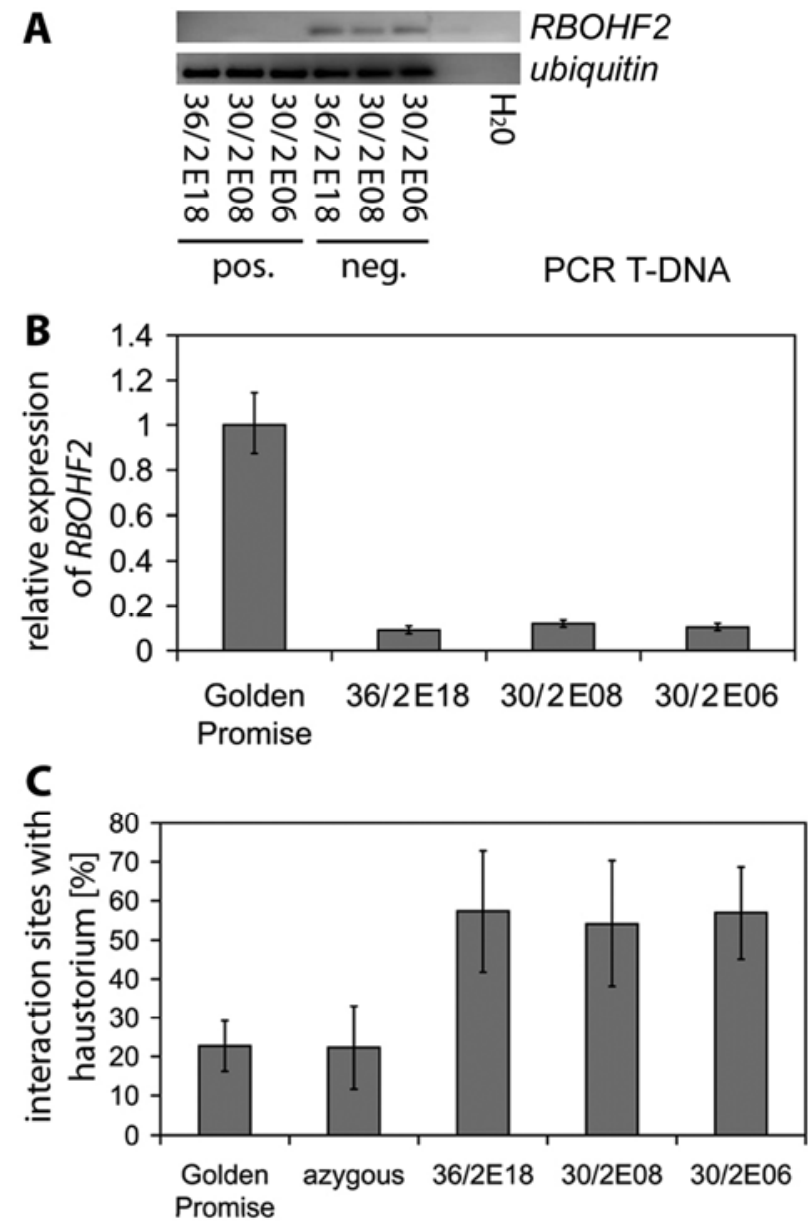

Fig. 1. Transcript amounts and susceptibility to fungal penetration in respiratory burst oxidase homologue $(R B O H) F 2$ knock down (KD) barley. A, Segregating $\mathrm{T} 1$ populations of three independent transgenic lines (36/2E18, 30/2E08, and 30/2E06) were tested for the presence of the RNAi construct by genomic polymerase chain reaction (PCR) and for the amount of $H v R B O H F 2$ transcript by reverse-transcription (RT)-PCR (32 cycles). RNA was extracted from a pool of four plants each followed by cDNA synthesis. Sibling that were positive (pos.) for the presence of the TDNA had strongly reduced amounts of $H v R B O H F 2$ transcript but unchanged amounts of the unrelated ubiquitin transcript. B, Quantitative RTPCR revealed that the amount of $H v R B O H F 2$ transcripts in lines having the RNAi construct was less than $20 \%$ of the wild-type level. RNA was extracted from a pool of four plants of the segregating T1 population, each followed by cDNA synthesis. Plants were genotyped for the presence of the hairpin construct by PCR on genomic DNA. Error bars show standard deviation of the three technical repetitions. C, Frequency of successful cell wall penetration and establishment of a fungal haustorium at interaction sites of wild-type Golden Promise, azygous siblings, and three $H v R B O H F 2 \mathrm{KD}$ lines. Error bars show confidence intervals of the means $(n=5)$ at $P=0.05$. chemical marker that distinguished nonpenetrated from penetrated cells in the interaction of barley with B. graminis f. sp. hordei (Hückelhoven et al. 1999, 2000). However, the function of $\mathrm{O}_{2} \cdot{ }^{-}$production was more enigmatic because $\mathrm{O}_{2} \cdot{ }^{-}$-mediated nitroblue tetrazolium reduction to formazans was associated with successful fungal penetration and with postpenetration MLA12-mediated race-specific immunity. The synthetic flavinenzyme inhibitor of RBOH diphenylene iodonium chloride did not effectively block ROS production but limited normal development of B. graminis f. sp. hordei (Hückelhoven and Kogel 1998). Superoxide was also detectable in cells neighboring hypersensitive single-cell death. These cells normally survive supporting a potential role of $\mathrm{O}_{2}{ }^{-}$in cell survival (Jabs et al. 1996; Hückelhoven and Kogel 2003; Trujillo et al. 2004).

Here, we produced transgenic barley plants with stably knocked down expression of HVRBOHF2, a RESPIRATORY BURST OXIDASE HOMOLOGOUS NADPH oxidase gene, and analyzed them for their interaction phenotype with $B$. graminis f. sp. hordei. Plants showed developmental failure from the three-leaf stage onward. Seedlings (14 to 20 days old) showed strongly enhanced susceptibility to penetration by virulent $B$. graminis f. sp. hordei before developmental failure occurred but little alteration of the local oxidative burst. Data support an involvement of monocot $\mathrm{RBOH}$ expression in normal development of penetration resistance to $B$. graminis $\mathrm{f}$. $\mathrm{sp}$. hordei and in control of leaf cell death.

\section{RESULTS}

To gain a deeper understanding of function of the NADPH oxidase HvRBOHF2 (formerly called HvRBOHA) in entire plants, we designed an antisense-intron-sense vector for stable knock down (KD) of HvRBOHF2 in transgenic barley (Hordeum vulgare L., cv. Golden Promise). We used the maize ubiquitin promoter $\mathrm{ZmUbi}$, which is ubiquitously active in barley (Schultheiss et al. 2005; Hensel et al. 2008). By the use of this construct, we produced T0 plants regenerated after Agrobacterium-mediated transformation of immature embryos. T0 plants showed a slightly reduced ability to set seed when compared with other defense-related constructs (Hensel et al. 2008). We tested T1 and T2 progenies for nonspecific resistance to virulent $B$. graminis f. sp. hordei 14 to 20 days after germination. Microscopic evaluation revealed that six of nine independent transgenic lines displayed enhanced susceptibility to fungal penetration on excised leaf segments. Penetration efficiency was quantified by counting haustoria at 100 interaction sites/ leaf. We tested three of these lines for expression of $H v R B O H F 2$ by semiquantitative and quantitative reverse-transcription polymerase chain reaction (qRT-PCR), and all three had strongly reduced levels of $H v R B O H F 2$ transcripts when compared with wild-type and azygous siblings that had lost the construct due to segregation (Fig. 1A and B). According to these experiments, the HvRBOHF2 transcript level in the RNAi lines was less than $20 \%$ of that in the wild type. Two independent inoculation experiments with these three lines were used for quantification of haustoria on leaf segments and led to the same results (Fig. 1C). Inoculation of intact $H v R B O H F 2 \mathrm{KD}$ plants instead of excised leaf segments also resulted in a similar rate of enhanced susceptibility to fungal penetration in $H v R B O H F 2$-silenced lines. In contrast, three lines that carried the T-DNA but were not silenced for $H v R B O H F 2$ had wildtype levels of resistance and, later, developed normally (data not shown). Segregation rates of approximately 2.6:1 (line 36/2E18), 2.7:1 (line 30/2E06), or 13:1 (line 30/2E08) suggested that these three lines had integrated the T-DNA at one or two loci. Genomic PCR confirmed that all individuals of these three lines that carried the hygromycin resistance gene 
used for selection also carried both of the inverted repeats designed to form a double-stranded (ds)RNA (data not shown).

\section{Co-silencing of $\mathrm{HvRBOHF2}$ and $\mathrm{HvRBOHF1.}$}

Newly available sequence information revealed that the cDNA fragment (accession AJ251717.1) used to construct the $H v R B O H F 2 \mathrm{KD}$ plants targeted a relatively conserved part of the gene. Therefore, we tested the specificity of the KD for $H v R B O H F 2$ by assessing gene expression levels of leafexpressed isoforms of RBOH (Lightfoot et al. 2008), namely F2, F1, E, and J. According to this analysis, both F2 and F1 isoforms were co-silenced in our KD plants whereas expression of isoforms $\mathrm{E}$ and $\mathrm{J}$ was unaffected (Fig. 2).

\section{$H v R B O H F 2$ KD does not affect ROS production.}

We stained wild-type and supersusceptible $H v R B O H F 2 \mathrm{KD}$ barley with 3,3-diaminobenzidine (DAB) for peroxidase-dependent detection of $\mathrm{H}_{2} \mathrm{O}_{2}$. The total frequency of interaction sites with $\mathrm{DAB}$ staining was not dramatically reduced in $H v R B O H F 2 \mathrm{KD}$ plants. However, the localization of DAB staining slightly changed. There was a tendency for more cells with DAB-stained anticlinal cell walls and fewer cells with

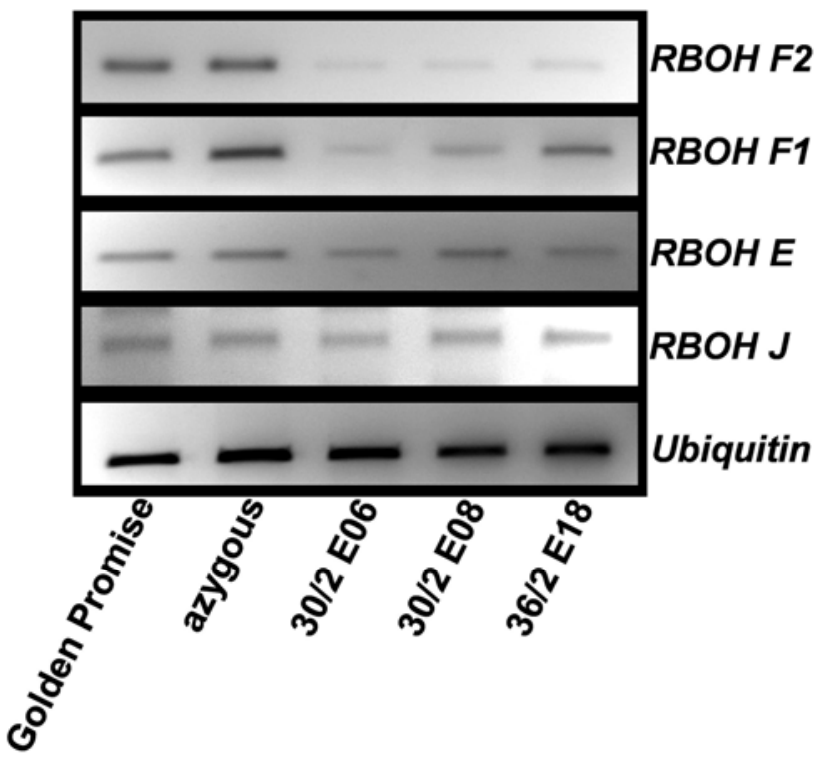

Fig. 2. Transcript levels of respiratory burst oxidase homologue $(R B O H)$ family members in barley leaves. Six leaves each of wild-type Golden Promise, one azygous line, and three $H v R B O H F 2$ knock down lines (30/2E06, 30/2E08, and 36/2E18) were extracted for RNA and subsequently analyzed by reverse-transcription polymerase chain reaction (RT-PCR) (28 cycles, except for RBOH F1 [30 cycles] and ubiquitin [25 cycles]) with primers specific for the different isoforms of RBOHs. Pictures show inverted photographs of ethidium-bromide-stained gels after electrophoresis of RT-PCR products.

Fig. 3. 3,3-Diaminobenzidine (DAB)-stainable oxidative burst in barley respiratory burst oxidase homologue $(R B O H) F 2$ knock down lines $24 \mathrm{~h}$ after inoculation. Brownish DAB-stainable oxidative burst was observed in $\mathbf{A}$, in papilla (PAP) bar $=15 \mu \mathrm{m} ; \mathbf{B}$, anticlinal cell walls $(\mathrm{ACW})$, bar $=15$ $\mu \mathrm{m}$; or $\mathbf{C}$, hypersensitive reaction (HR) cells, bar $=40 \mu \mathrm{m}$. D, Frequencies of DAB staining pattern in Golden Promise, azygous siblings, and three RNAi lines; 80 to 120 interaction sites per leaf of four to six leaves per line were analyzed. Error bars show confidence intervals at $P=0.05$. Letters $\mathrm{A}, \mathrm{B}$, or $\mathrm{AB}$ in the upper part (PAP DAB) and middle part (ACW $\mathrm{DAB}$ ) show the grouping of data sets according to Tukey's highly significant difference (HSD) test at $P=0.05$. HR data sets represent just one group according to Tukey's HSD test.
DAB-stained papillae beneath appressoria, when $H v R B O H F 2$ expression was down (Fig. 3).

To assess the ability of $H v R B O H F 2 \mathrm{KD}$ plants to respond to stimuli other than $B$. graminis f. sp. hordei, we treated leaf discs with the flagellin elicitor peptide flg22 and measured the
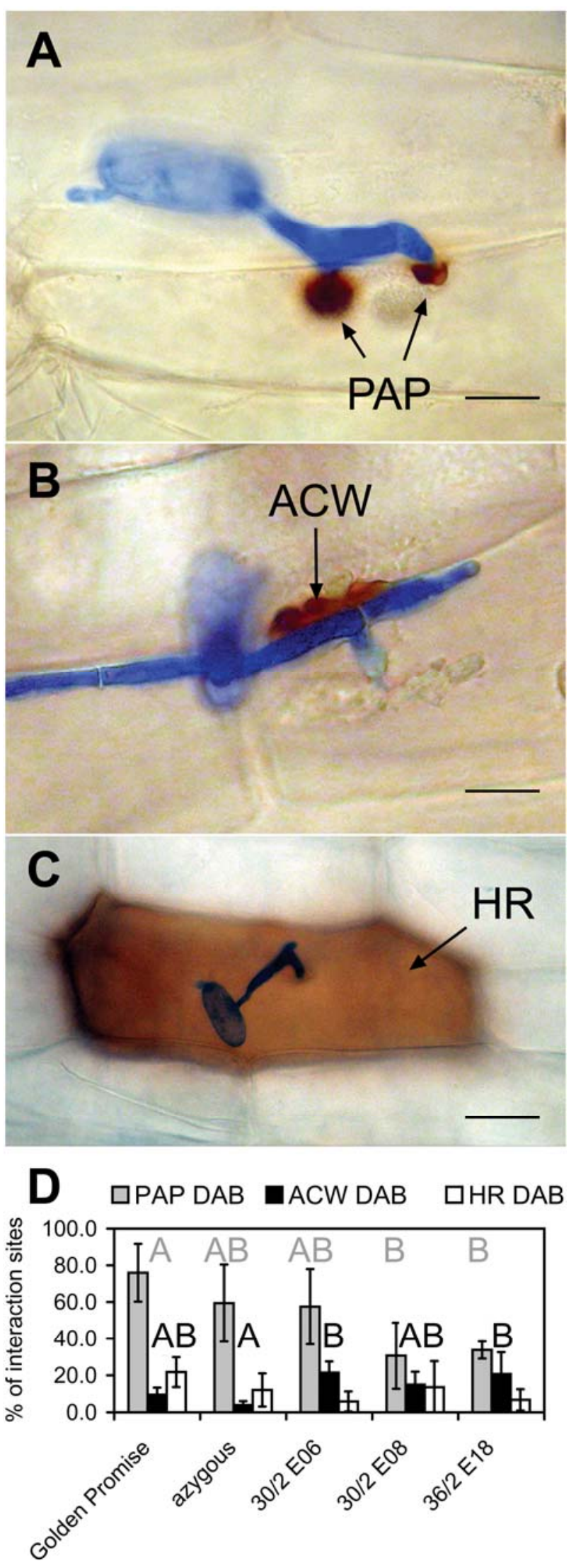

Vol. 23, No. 9, $2010 / 1145$ 
oxidative burst by a chemiluminescence assay based on oxidation of luminol. In four repetitions, we observed no strong difference between the flg22-triggered oxidative burst in wildtype and $H v R B O H F 2 \mathrm{KD}$ leaves (Fig. 4).

\section{Pleiotropic effects of $\mathrm{HvRBOHF2} \mathrm{KD}$.}

When we challenged young $H v R B O H F 2 \mathrm{KD}$ plants by $B$. graminis f. sp. hordei, plants had a wild-type appearance. However, after 3 to 5 weeks under controlled climate in a phytochamber, $H v R B O H F 2 \mathrm{KD}$ lines displayed reduced tillering, necrotic leaf spotting, and less stability when compared with wild-type or azygous segregants (Fig. 5A to C). Trypan blue staining of fully developed leaves 14 to 21 days after leaf emergence showed spontaneous mesophyll cell death (Fig. 5D and E). During propagation of the lines under less-well-controlled glasshouse conditions, a subset of $H v R B O H F 2 \mathrm{KD}$ plants failed to set seed or possessed a reduced number of spikelets per spike that filled. This was not observed in wildtype plants or azygous siblings under the same conditions. When $H v R B O H F 2$ KD leaves were wounded by cutting, a slowly progressing leaf necrosis was observed, starting from the site of wounding (Fig. 5F to $\mathrm{H}$ ). This type of necrosis progressed until the entire leaf was gone (10 to 20 days after wounding) but no systemic spreading of leaf necrosis to other leaves was observed.

\section{DISCUSSION}

Here, we provided evidence for function of RBOH-type NADPH oxidases in development of basal resistance to penetration by a parasitic fungus and in control of leaf cell death in the monocot barley. There are several studies on the function of
$\mathrm{RBOH}$ oxidases in dicots such as Arabidopsis, tobacco, potato, and tomato (Torres et al. 2002) but genetic evidence on the function of monocots $\mathrm{RBOH}$ is sparse and derived from single-cell transformation (Trujillo et al. 2006). Ballistic single-cell transformation is a reliable measure for assessing gene functions in interaction of members of the tribe Triticeae and powdery mildew fungi (Panstruga 2004). In many cases, transient ballistic transformation of a certain gene resulted in an impact on the interaction similar to stable transformation or introgression of the same gene into barley or wheat (Shirasu et al. 1999; Haltermann et al. 2001; Azevedo et al. 2002; Collins et al. 2003; Altpeter et al. 2005; Schultheiss et al. 2005; Schweizer 2007; Babaeizad et al. 2009). However, for HvRBOHF2, single-cell gene silencing by the use of in vitro-generated dsRNA resulted in reduced susceptibility (Trujillo et al. 2006), whereas stable gene KD resulted in enhanced susceptibility to the same pathogen. This discrepancy might be explained by non-cell autonomous function of HvRBOHF2 in interaction with $B$. graminis $\mathrm{f}$. sp. hordei, which cannot be detected at the single-cell level. Alternatively, loss of functions of HvRBOHF2 during plant development might have conditioned KD plants for higher susceptibility to $B$. graminis $\mathrm{f}$. sp. horde $i$. This possibility is underscored because $H v R B O H F 2$ is more strongly expressed during early development of barley leaves than in fully developed leaves (Hückelhoven et al. 2001). Hence, HvRBOHF2 might have distinct functions in fully developed leaves when compared with a developing leaf. Independent of this conflict, our results clearly show that successful, stable KD of $H v R B O H F 2$ is associated with a significant loss of penetration resistance to $B$. graminis $\mathrm{f}$. sp. hordei. Penetration of the plant cell wall by $B$. graminis $\mathrm{f}$. $\mathrm{sp}$. hordei is achieved by mechanical force and hydrolytic activity (Pryce-Jones et al. 1999). Phylogenetic analysis of HvRBOH

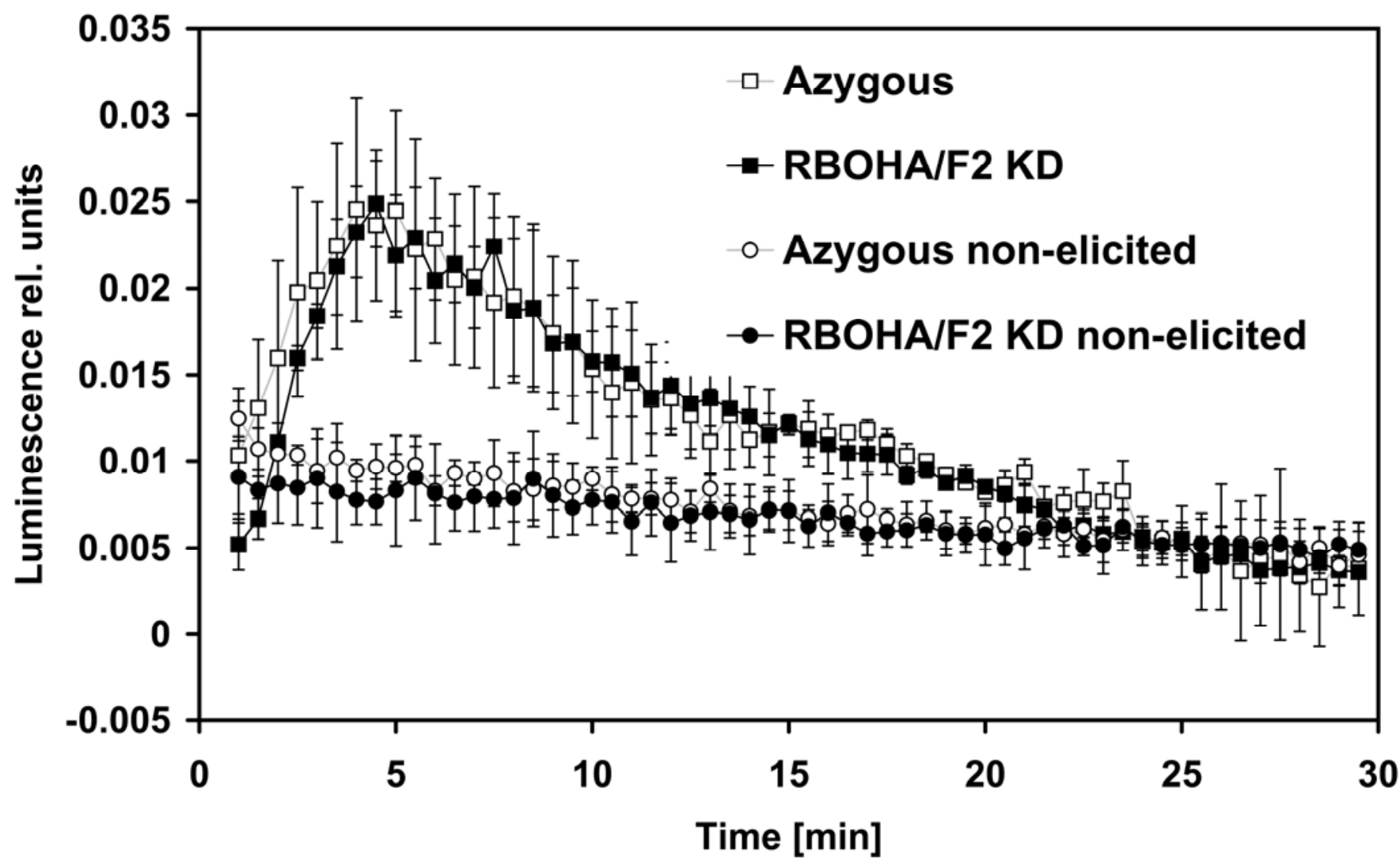

Fig. 4. Flg22-triggered oxidative burst in azygous siblings (Azygous) and respiratory burst oxidase homologue $(R B O H) A / F 2$ knock down (KD) line $36 / 2$ E18 $(R B O H A / F 2 K D)$. At time point zero, $1 \mu \mathrm{M}$ flg22 was added to the leaf discs and, subsequently, reactive oxygen species-mediated oxidation of luminol was recorded as chemiluminescence for $30 \mathrm{~min}$. Nonelicited controls were identically treated except for the lack of flg22. Data show the mean and standard deviation of four individual plants each. Similar results were obtained for line 36/2 E06. 
oxidases showed that $H v R B O H F 2$ and $H v R B O H F 1$ are very similar in sequence and gene structure (Lightfoot et al. 2008) and, thus, potential products of an evolutionary recent gene duplication. Hence, HvRBOHF2 or the co-silenced HvRBOHF1 or both might function in formation or strengthening of cell walls. Arabidopsis AtRBOHC was shown to function in cell wall stability of root cells (Macpherson et al. 2008). However, a protoplast release assay did not indicate accelerated protoplast release from $H v R B O H F 2 \mathrm{KD}$ leaves (data not shown).

The AtRBOHF gene is the nearest relative of barley HvRBOHF2 and HvRBOHF1 in Arabidopsis (Trujillo et al. 2006; Lightfoot et al. 2008). Knock-out atrbohF mutants partially or fully retained the ability to respond to a bacterial, oomycete, or fungal pathogen with an oxidative burst (Torres et al. 2002; Pogány et al. 2009). To assess the function of HvRBOHF2 or HvRBOHF1 in oxidative defense during pathogen invasion, we stained leaves with DAB. This showed that $H v R B O H F 2 \mathrm{KD}$ affected the pattern rather than the total frequency of DAB staining at the site of interaction with $B$. graminis f. sp. hordei. We observed $\mathrm{H}_{2} \mathrm{O}_{2}$ less frequently in CWA but more frequently in anticlinal cell walls close to fungal attacks. $\mathrm{H}_{2} \mathrm{O}_{2}$ production at anticlinal cell walls was previously reported to be associated with successful fungal penetration whereas $\mathrm{H}_{2} \mathrm{O}_{2}$ in CWA is indicative of successful penetration defense (Hückelhoven et al. 1999, 2000). Together with the general ability of $H v R B O H F 2 \mathrm{KD}$ barley to produce $\mathrm{H}_{2} \mathrm{O}_{2}$ at sites of interaction, we interpret the change of pattern of DAB staining as a consequence rather than as a cause of enhanced susceptibility. Additionally, $H v R B O H F 2 \mathrm{KD}$ plants were not substantially affected in the oxidative burst to the fungus-unrelated bacterial elicitor flg22 (Gomez-Gomez et al. 1999) (Fig. 4). This shows that enzymes other than HvRBOHF2 may be alternative sources of ROS in both flagellin elicitor response and in interaction with $B$. graminis f. sp. hordei.

$\mathrm{KD}$ of $H v R B O H F 2$ caused pleiotropic effects, suggesting a function of $\mathrm{RBOH}$ oxidases during normal development of monocots. Similarly, KD of a tomato $\mathrm{RBOH}$ caused developmental failure (Sagi et al. 2004) and knock out of Arabidopsis AtRBOHF caused a dwarf phenotype and ectopic cell death in elder plants. This was enhanced when AtRBOHD was simultaneously knocked out (Torres et al. 2002). Very similarly, our plants with KD of the $H v R B O H F$ clade have developmental retardation and show cell death in elder leaves. This supports a function of the monocot and dicot RBOHF clade of RBOH oxidases in normal plant development and in control of senescenceassociated cell death. Additionally, a role for $\mathrm{RBOH}$ oxidases in protecting cells from pathogen- or elicitor-induced cell damage was demonstrated (Torres et al. 2005; Lherminier et al. 2009; Pogány et al. 2009). Most recently, Yi and co-workers (2010) have shown that ectopic overexpression of a pepper receptor-like kinase in $N$. benthamiana causes overexpression of several $\mathrm{RBOH}$ oxidases accompanied by enhanced superoxide production and reduced cell death upon bacterial infection.

$\mathrm{RBOH}$ oxidases are involved in local and systemic wounding-induced ROS production and downstream responses (Orozco-Cardenas et al. 2001; Sagi et al. 2004; Kumar et al. 2007; Miller et al. 2009). In plants, wound-induced leaf necrosis is normally restricted to the zone directly associated with the actual site of wounding. KD of $H v R B O H F 2$, however, caused a spreading leaf necrosis starting from the cut and progression to the leaf basis within several days to 2 weeks after wounding, whereas no progressive necrosis was observed in wild-type barley. The actual speed of progressive necrosis was variable but can be judged as slow. This points to a role of barley F-clade $\mathrm{RBOH}$ oxidases in restricting wound-induced cell death in barley. There are several types of cell death described, such as senescence-induced cell death, pathogen-induced HR,

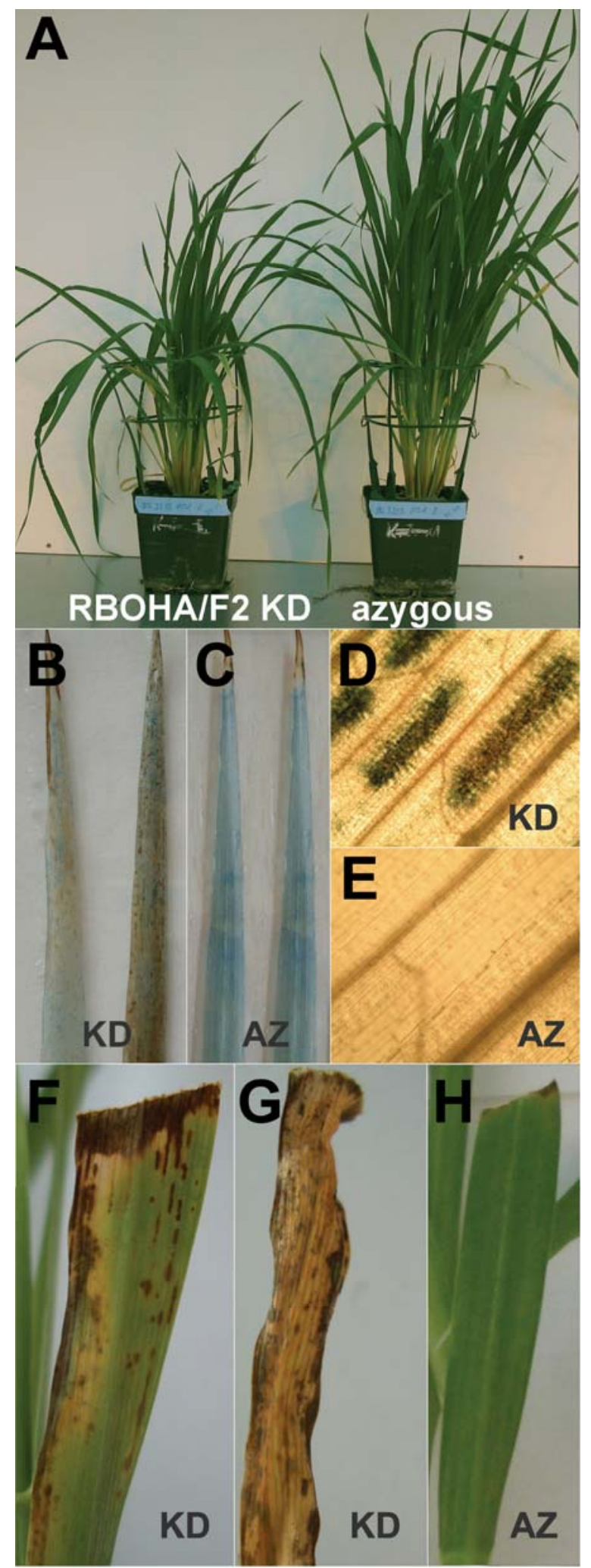

Fig. 5. Phenotype of barley respiratory burst oxidase homologue $(R B O H) A / F 2$-RNAi lines. A, Six-week-old $H v R B O H F 2$ knock down (KD) barley was retarded in development when compared with an azygous sister plant that lost the T-DNA due to segregation. B, Adult leaves (destained) of KD plant show spontaneous brown leaf spotting, $\mathbf{C}$, which is not seen in azygous siblings (AZ). D, Trypan blue staining of fully developed leaves 20 days after emergence reveals nests of dead mesophyll cells, E, which are not seen in azygous controls. F, Cut-induced runaway cell death is seen in $H v R B O H A / F 2$ KD plants 5 days after cutting and $\mathbf{G}$, progresses until the entire leaf is dead. In contrast, leaf cell death remains locally restricted at $\mathbf{H}$, the cut in azygous siblings or the wild type (not shown). 
or abiotic stress-triggered cell death (Lam 2004). Here, we show that KD of $H v R B O H F 2$ affects two types of cell death responses, the senescence-related cell death in elder leaves and wound-induced necrosis, but the HR was not affected. The observed cell death also does not resemble the leaf tip cell death as recently reported of the $B$. graminis $\mathrm{f}$. $\mathrm{sp}$. horde $i$-induced tip cell death1 mutant, $b c d 1$ (Xi et al. 2009). Following mildew inoculation, $\mathrm{Xi}$ and associates (2009) described a cell death phenotype in bcdl starting at the leaf tips and spreading throughout the upper part of the leaf. Although B. graminis $\mathrm{f}$. sp. hordei is a rapid, highly synchronous inducer of the observed phenotype, the $b c d l$-mediated cell death also occurs over developmental time. In contrast, the spreading leaf necrosis reported in this study is triggered by wounding but not by powdery mildew. HR-related epidermal cell death was unaffected by $\mathrm{KD}$ of $H v R B O H F 2$ (Fig. 3D). Together, our data represent evidence for a function of RBOH oxidases in monocots at the entire plant level and support a complex function of $\mathrm{RBOH}$ oxidases in plant development, interaction with the environment, and ability to locally restrict leaf cell death.

\section{MATERIALS AND METHODS}

\section{Plant and pathogen material and inoculation.}

Donor material and transgenic plants of the barley $(H . v u l$ gare L.) cv. Golden Promise were grown in a growth chamber at $18^{\circ} \mathrm{C}, 60 \%$ relative humidity, and a photoperiod of $16 \mathrm{~h}$ (150 $\mu \mathrm{mol} \mathrm{s}{ }^{-1} \mathrm{~m}^{-2}$ photon flux density) up to E.C. 30. From the fifth week after germination onward, plants were grown in a greenhouse at $20^{\circ} \mathrm{C}$. Blumeria graminis (DC.) Speer f. sp. hordei Em. Marchal, race A6 (Wiberg 1974), undergoes a compatible interaction with the barley lines used and was maintained on Golden Promise under the same conditions. For microscopic evaluation, B. graminis f. sp. hordei was inoculated onto detached second or third leaves of 14- to 20-day-old barley plants to give a density of 20 conidia $\mathrm{mm}^{-2}$.

\section{Cloning and plant transformation.}

Stable genetic transformation of barley with pLH6000ZmUbi::antisenseHvRBOHF2-intron-senseHvRBOHF2-nos was performed by Agrobacterium-mediated genetic transformation as described by Hensel and associates (2008). Constructs were generated by cloning a cDNA fragment of $H v R B O H F 2$ (accession AJ251717.1) (Hückelhoven et al. 2001) (full-length sequence, accession AM265370) (Trujillo et al. 2006) into the multiple cloning sites of the RNAi vector pJP26 (provided by R. Dudler, University of Zurich, Switzerland). The entire senseintron antisense construct was then subcloned into pUBI-AB behind the maize ubiquitin promoter and first intron of maize ubiquitin and in front of the nos terminator. Subsequently, ZmUbi::HvRBOHF2antisense:intron:HvRBOHF2sense:nos was subcloned into pLH6000 via Sfi restriction sites for Agrobacterium-mediated transformation of immature embryos (Schultheiss et al. 2005; Hensel et al. 2008).

\section{Analysis of segregating populations \\ of transgenic barley lines using genomic PCR.}

Segregating individuals of transgenic barley lines were tested by genomic PCR. For genomic DNA isolation, leaf discs were excised using the lid of a $1.5-\mathrm{ml}$ reaction tube and ground in presence of $400 \mu \mathrm{l}$ of extraction buffer $(200 \mathrm{mM}$ Tris [pH 7.5], $250 \mathrm{mM} \mathrm{NaCl}, 25 \mathrm{mM}$ EDTA, and $0.5 \%$ sodium dodecyl sulfate). Debris was removed by centrifugation for $1 \mathrm{~min}$ at $13,000 \mathrm{rpm}$, and $300 \mu \mathrm{l}$ of supernatant was added to $300 \mu \mathrm{l}$ of isopropanol. Samples were incubated for $2 \mathrm{~min}$ at room temperature and centrifuged for $5 \mathrm{~min}$ at $13,000 \mathrm{rpm}$ to precipitate DNA. The DNA pellet was dried and resuspended in
$100 \mu \mathrm{l}$ of Tris-EDTA buffer (10 mM Tris/HCl, $\mathrm{pH} 7.5$, and 2 mM EDTA, pH 8.0). Genomic DNA $(3 \mu \mathrm{l})$ was used as template for PCR amplification with the primers RbohRNAi1 (5'CATCACAATGCTGCAAGCTCT-3') and RbohRNAi2 (5'-A TGCTCTAACCTTGAGTACCTATC-3'). Resulting PCR products were analyzed by agarose-gel electrophoresis. Additionally, phenotypes of transgenic plants, as visible in later stages of plant development, were used to confirm the transgenic nature of individuals. Segregants that lost the transgene due to segregation were used as azygous controls in all experiments. Azygous controls from individual lines behaved similarly. Previous experiments had shown that populations of azygous segregants behaved in development and pathogen response like the wildtype parent Golden Promise plants (not shown).

\section{RT-PCR and quantitative real-time PCR.}

Total RNA was extracted from leaf material from 10-day-old seedlings. Four to six leaves of each line were pooled prior to RNA extraction. Isolated RNA was treated with DNase and cDNA was synthesized using the iScript cDNA synthesis kit (Bio-Rad, Hercules, CA, U.S.A.) following the manufacturer's instructions. For semiquantitative RT-PCR, $50 \mathrm{ng}$ of cDNA served as template and specific products were amplified in 25 to 32 PCR cycles, as indicated, using primer pairs as described by Lightfoot and associates (2008). To amplify the reference gene ubiquitin and to generate data presented in Figure 1A, primer pairs for ubiquitin and $H v R B O H A / F 2$ were used as described for qRT-PCR. qRT-PCR was performed in a Mx3005P Cycler (Stratagene, La Jolla, CA, U.S.A.) using the iTaq SYBR Green Supermix with ROX as reference dye ( Bio$\mathrm{Rad})$. Primers were designed to allow amplification of the reference gene ubiquitin (forward 5'-ACCCTCGCCGACTACAA CAT-3' and reverse 5'-CAGTAGTGGCGGTCGAAGTG-3') or $H v R B O H A / F 2$ (forward 5'-CCGATCAGATGTATGCTCCA$3^{\prime}$ and reverse 5'-CAGAAGGCATTGAAGCCAGT-3') as described previously (Trujillo et al. 2006). Reactions contained $10 \mu \mathrm{l}$ of reaction mixture, $100 \mathrm{ng}$ of cDNA, and $0.5 \mathrm{pmol}$ of each primer in a total volume of $20 \mu \mathrm{l}$. All reactions were carried out in triplicate for each sample. PCR for quantification started with $7 \mathrm{~min}$ of denaturation at $95^{\circ} \mathrm{C}$ followed by 40 cycles of $95^{\circ} \mathrm{C}$ for $30 \mathrm{~s}, 60^{\circ} \mathrm{C}$ for $30 \mathrm{~s}$, and $72^{\circ} \mathrm{C}$ for $40 \mathrm{~s}$ (fluorescence acquiring at the end of each cycle). Subsequently, a melting curve was performed in which temperature was shifted to $95^{\circ} \mathrm{C}$ for $1 \mathrm{~min}, 60^{\circ} \mathrm{C}$ for $30 \mathrm{~s}$, and again to $95^{\circ} \mathrm{C}$ for $30 \mathrm{~s}$. Identity of qRT-PCR products was confirmed by the observation of a single melting peak.

\section{Histological staining and microscopic analysis.}

The outcome of the interaction of transgenic barley plants with B. graminis f. sp. horde $i$ was evaluated 24 and $48 \mathrm{~h}$ after inoculation. Penetration of attacked cells was ascertained by detection of haustoria formation. Penetration efficiency was quantified by counting haustoria at 100 interaction sites per leaf of four to seven leaves per line and experiment. Staining with DAB was taken as reliable markers of $\mathrm{H}_{2} \mathrm{O}_{2}$ accumulation (Hückelhoven et al. 1999; Thordal-Christensen et al. 1997). Bright-field and fluorescence microscopy was performed as described by Hückelhoven and Kogel (1998). Because the rate of fungal penetration into short and long epidermal cells is different, only short cells (cell type A and B) (Koga et al. 1990) were evaluated. We exclusively evaluated interaction sites where only one fungus per cell attempted to penetrate.

\section{Measuring the flg22-triggered oxidative burst.}

Leaves of 10-day-old barley seedlings were harvested, cut in small square pieces of $4 \mathrm{~mm}^{2}$ in size, and floated on tap water overnight. Two leaf pieces each were placed in wells of a 96- 
well multi-titer plate containing $200 \mu \mathrm{l}$ of the reaction mixture (0.02 mM 5-amino-2,3-dihydro-1,4-phthalazinedione, horseradish peroxidase at $0.02 \mathrm{U} / \mathrm{ml}$, and $5 \mathrm{mM}$ sodium phosphate buffer, pH8.0) and preincubated in the dark for $15 \mathrm{~min}$. Immediately after adding $1 \mu \mathrm{M}$ flg 22 , the luminescence was followed for $30 \mathrm{~min}$ at 30-s intervals using a photomultiplier (Berthold Biolumat 9500; Bad Wildbad, Germany).

\section{ACKNOWLEDGMENTS}

We thank A. Muhr, C. Marthe, and H. Nierig for excellent technical assistance. This work was supported by grants from the Deutsche Forschungsgemeinschaft (HU886/5) and a BMBF GABI-Agrotec grant to J. Kumlehn.

\section{LITERATURE CITED}

Achard, P., Renou, J. P., Berthomé, R., Harberd, N. P., and Genschik, P. 2008. Plant DELLAs restrain growth and promote survival of adversity by reducing the levels of reactive oxygen species. Curr. Biol. 18:656660.

Altpeter, F., Varshney, A., Abderhalden, O., Douchkov, D., Sautter, C., Kumlehn, J., Dudler, R., and Schweizer, P. 2005. Stable expression of a defense-related gene in wheat epidermis under transcriptional control of a novel promoter confers pathogen resistance. Plant Mol. Biol. 57:27183.

An, Q., Hückelhoven, R., Kogel, K.-H., and van Bel, A. J. E. 2006. Multivesicular bodies participate in a cell wall-associated defence response in barley leaves attacked by the pathogenic powdery mildew fungus. Cell Microbiol. 8:1009-1019.

Azevedo, C., Sadanandom, A., Kitagawa, K., Freialdenhoven, A., Shirasu, K., and Schulze-Lefert, P. 2002. The RAR1 interactor SGT1, an essential component of $R$ gene-triggered disease resistance. Science 295:20732076 .

Babaeizad, V., Imani, J., Kogel, K.-H., Eichmann, R., and Hückelhoven, R. 2009. Over-expression of the cell death regulator BAX inhibitor-1 in barley confers reduced or enhanced susceptibility to distinct fungal pathogens. Theor. Appl. Genet. 118:455-463.

Collins, N. C., Thordal-Christensen, H., Lipka, V., Bau, S., Kombrink, E., Qiu, J.-L., Hückelhoven, R., Stein, M., Freialdenhoven, A., Somerville, S. C., and Schulze-Lefert, P. 2003. SNARE-protein-mediated disease resistance at the plant cell wall. Nature 425:973-977.

Desikan, R., Last, K., Harrett-Williams, R., Tagliavia, C., Harter, K., Hooley, R., Hancock, J. T., and Neill, S. J. 2006. Ethylene-induced stomatal closure in Arabidopsis occurs via AtrbohF-mediated hydrogen peroxide synthesis. Plant J. 47:907-916.

Foreman, J., Demidchik, V., Bothwell, J. H., Mylona, P., Miedema, H., Torres, M. A., Linstead, P., Costa, S., Brownlee, C., Jones, J. D., Davies, J. M., and Dolan, L. 2003. Reactive oxygen species produced by NADPH oxidase regulate plant cell growth. Nature 422:442-446.

Gómez-Gómez, L., Felix, G., and Boller, T. 1999. A single locus determines sensitivity to bacterial flagellin in Arabidopsis thaliana. Plant J. 18:277-84.

Halterman, D., Zhou, F., Wei, F., Wise, R. P., and Schulze-Lefert, P. 2001. The MLA6 coiled-coil, NBS-LRR protein confers AvrMla6-dependent resistance specificity to Blumeria graminis f. sp. hordei in barley and wheat. Plant J. 25:335-348.

Hensel, G., Valkov, V., Middlefell-Williams, J., and Kumlehn, J. 2008. Efficient generation of transgenic barley: the way forward to modulate plant-microbe interactions. J. Plant Physiol. 165:71-82.

Hückelhoven, R., and Kogel, K.-H. 1998. Tissue-specific superoxide generation at interaction sites in resistant and susceptible near-isogenic barley lines attacked by the powdery mildew fungus (Erysiphe graminis $\mathrm{f}$. sp. hordei). Mol. Plant-Microbe Interact. 11:292-300.

Hückelhoven, R., and Kogel, K.-H. 2003. Reactive oxygen intermediates in plant-microbe interactions: who is who in powdery mildew resistance? Planta 216:891-902.

Hückelhoven, R., Fodor, J., Preis, C., and Kogel, K.-H. 1999. Hypersensitive cell death and papilla formation in barley attacked by the powdery mildew fungus are associated with $\mathrm{H}_{2} \mathrm{O}_{2}$ but not with salicylic acid accumulation. Plant Physiol. 119:1251-1260.

Hückelhoven, R., Trujillo, M., and Kogel, K.-H. 2000. Mutations in Rorl and Ror 2 genes cause modification of hydrogen peroxide accumulation in $m l o$-barley under attack from the powdery mildew fungus. Mol. Plant Pathol. 1:287-292.

Hückelhoven, R., Dechert, C., Trujillo, M., and Kogel, K.-H. 2001. Differential expression of putative cell death regulator genes in near-isogenic, resistant and susceptible barley lines inoculated with the powdery mildew fungus. Plant Mol. Biol. 47:739-748.

Jabs, T., Dietrich, R. A., and Dangl, J. L. 1996. Initiation of runaway cell death in an Arabidopsis mutant by extracellular superoxide. Science 273:1853-1856.

Koga, H., Bushnell, W. R., and Zeyen, R. J. 1990. Specificity of cell type and timing of events associated with papilla formation and the hypersensitive reaction in leaves of Hordeum vulgare attacked by Erysiphe graminis f. sp. hordei. Can. J. Bot. 68:2344-2352.

Kumar, G. N., Iyer, S., and Knowles, N. R. 2007. Strboh A homologue of NADPH oxidase regulates wound-induced oxidative burst and facilitates wound-healing in potato tubers. Planta 227:25-36.

Lam, E. 2004. Controlled cell death, plant survival and development. Nat. Rev. Mol. Cell Biol. 5:305-315.

Lamb, C., and Dixon, R. A. 1997. The oxidative burst in plant disease resistance. Annu. Rev. Plant Physiol. Plant Mol. Biol. 48:251-275.

Lherminier, J., Elmayan, T., Fromentin, J., Elaraqui, K. T., Vesa, S., Morel, J., Verrier, J. L., Cailleteau, B., Blein, J. P., and Simon-Plas, F. 2009. NADPH oxidase-mediated reactive oxygen species production: subcellular localization and reassessment of its role in plant defense. Mol Plant-Microbe Interact. 22:868-881.

Lightfoot, D. J., Boettcher, A., Little, A., Shirley, N., and Able, A. J. 2008. Identification and characterisation of barley (Hordeum vulgare) respiratory burst oxidase homologue family members. Funct. Plant Biol. 35:347-359.

Macpherson, N., Takeda, S., Shang, Z., Dark, A., Mortimer, J. C., Brownlee, C., Dolan, L., and Davies, J. M. 2008. NADPH oxidase involvement in cellular integrity. Planta 227:1415-1418.

Miller, G., Schlauch, K., Tam, R., Cortes, D., Torres, M. A., Shulaev, V., Dangl, J. L., and Mittler, R. 2009. The plant NADPH oxidase RBOHD mediates rapid systemic signaling in response to diverse stimuli. Sci. Signal. 2:ra45.

Murata, Y., Pei, Z. M., Mori, I. C., and Schroeder, J. 2001. Abscisic acid activation of plasma membrane $\mathrm{Ca}^{2+}$ channels in guard cells requires cytosolic $\mathrm{NAD}(\mathrm{P}) \mathrm{H}$ and is differentially disrupted upstream and downstream of reactive oxygen species production in abil-1 and abi2-1 protein phosphatase 2C mutants. Plant Cell 13:2513-2523.

Nühse, T. S., Bottrill, A. R., Jones, A. M., and Peck, S. C. 2007. Quantitative phosphoproteomic analysis of plasma membrane proteins reveals regulatory mechanisms of plant innate immune responses. Plant J. 51:931-940.

Orozco-Cárdenas, M. L., Narváez-Vásquez, J., and Ryan, C. A. 2001. Hydrogen peroxide acts as a second messenger for the induction of defense genes in tomato plants in response to wounding, systemin, and methyl jasmonate. Plant Cell 13:179-191.

Panstruga, R. 2004. A golden shot: how ballistic single cell transformation boosts the molecular analysis of cereal-mildew interactions. Mol. Plant Pathol. 5:141-148.

Pathuri, P. I., Zellerhoff, N., Schaffrath, U., Hensel, G., Kumlehn, J., Kogel, K. H., Eichmann, R., and Hückelhoven, R. 2008. Constitutively activated barley ROPs modulate epidermal cell size, defense reactions and interactions with fungal leaf pathogens. Plant Cell Rep. 27:1877-1887.

Pogány, M., von Rad, U., Grün, S., Dongó, A., Pintye, A., Simoneau, P., Bahnweg, G., Kiss, L., Barna, B., and Durner, J. 2009. Dual roles of reactive oxygen species and NADPH oxidase RBOHD in an Arabidopsis-Alternaria pathosystem. Plant Physiol. 151:1459-1475.

Potocký, M., Jones, M. A., Bezvoda, R., Smirnoff, N., and Zárský, V. 2007. Reactive oxygen species produced by NADPH oxidase are involved in pollen tube growth. New Phytol. 174:742-751.

Pryce-Jones, E., Carver, T., and Gurr, S. J. 1999. The roles of cellulase enzymes and mechanical force in host penetration by Erysiphe graminis f. sp. hordei. Physiol. Mol. Plant Pathol. 55:175-182.

Sagi, M., Davydov, O., Orazova, S., Yesbergenova, Z., Ophir, R., Stratmann, J. W., and Fluhr, R. 2004. Plant respiratory burst oxidase homologs impinge on wound responsiveness and development in $L y$ copersicon esculentum. Plant Cell 16:616-628.

Schultheiss, H., Hensel, G., Imani, J., Broeders, S., Kumlehn, J., Kogel, K.H., Sonnewald, U., and Hückelhoven, R. 2005. Ectopic expression of constitutively activated RACB in barley enhances susceptibility to powdery mildew and abiotic stress. Plant Physiol. 139:353-362.

Schweizer, P. 2007. Tissue-specific expression of a defence-related peroxidase in transgenic wheat potentiates cell death in pathogen-attacked leaf epidermis. Mol. Plant Pathol. 9:45-57.

Shirasu, K., Nielsen, K., Piffanelli, P., Oliver, R., and Schulze-Lefert, P. 1999. Cell-autonomous complementation of mlo resistance using a biolistic transient expression system. Plant J. 17:293-300.

Thordal-Christensen, H., Zhang, Z., Wei, Y., and Collinge, D. B. 1997. Subcellular localization of $\mathrm{H}_{2} \mathrm{O}_{2}$ in plants, $\mathrm{H}_{2} \mathrm{O}_{2}$ accumulation in papillae, and hypersensitive response during the barley-powdery mildew interaction. Plant J. 11:1187-1194. 
Torres, M. A., Dangl, J. L., and Jones, J. D. 2002. Arabidopsis gp91phox homologues AtrbohD and AtrbohF are required for accumulation of reactive oxygen intermediates in the plant defense response. Proc. Natl. Acad. Sci. U.S.A. 99:517-522.

Torres, M. A., Jones, J. D., and Dangl, J. L. 2005. Pathogen-induced, NADPH oxidase-derived reactive oxygen intermediates suppress spread of cell death in Arabidopsis thaliana. Nat. Genet. 37:1130-1134.

Torres, M. A., Jones, J. D., and Dangl, J. L. 2006. Reactive oxygen species signaling in response to pathogens. Plant Physiol. 141:373-378.

Trujillo, M., Kogel, K.-H., and Hückelhoven, R. 2004. Superoxide and hydrogen peroxide play different roles in non-host interactions of cereals and inappropriate formae speciales of Blumeria graminis. Mol. PlantMicrobe Interact. 17:304-312.

Trujillo, M., Altschmied, L., Schweizer, P., Kogel, K.-H., and Hückelhoven, R. 2006. Respiratory Burst Oxidase Homologue A of barley contributes to penetration by the powdery mildew fungus Blumeria graminis $\mathrm{f}$. $\mathrm{sp}$. hordei. J. Exp. Bot. 57:3781-3791.

Wiberg, A. 1974. Genetical studies of spontaneous sources of resistance to powdery mildew in barley. Hereditas 77:89-148.

Wong, H. L., Pinontoan, R., Hayashi, K., Tabata, R., Yaeno, T., Hasegawa,
K., Kojima, C., Yoshioka, H., Iba, K., Kawasaki, T., and Shimamoto, K 2007. Regulation of rice NADPH oxidase by binding of Rac GTPase to its N-terminal extension. Plant Cell 19:4022-4034.

Xi, L., Moscou, M. J., Meng, Y., Xu, W., Caldo, R. A., Shaver, M. Nettleton, D., and Wise, R. P. 2009. Transcript-based cloning of RRP46, a regulator of rRNA processing and $R$ gene-independent cell death in barley-powdery mildew interactions. Plant Cell 21:3280-3295.

Yi, S. Y., Lee, D. J., Yeom, S. I., Yoon, J., Kim, Y. H., Kwon, S. Y., and Choi, D. 2010. A novel pepper (Capsicum annuum) receptor-like kinase functions as a negative regulator of plant cell death via accumulation of superoxide anions. New Phytol. 185:701-715.

Yoshie, Y., Goto, K., Takai, R., Iwano, M., Takayama, S., Isogai, A., and Che, F.-S. 2005. Function of the rice gp91phox homologs OsrbohA and OsrbohE genes in ROS-dependent plant immune responses. Plant Biotechnol. 22:127-135.

Yoshioka, H., Numata, N., Nakajima, K., Katou, S., Kawakita, K., Rowland, O., Jones, J. D., and Doke, N. 2003. Nicotiana benthamiana gp91phox homologs NbrbohA and NbrbohB participate in $\mathrm{H}_{2} \mathrm{O}_{2}$ accumulation and resistance to Phytophthora infestans. Plant Cell 15:706718. 